\title{
Tobacco mild green mosaic virus found naturally infecting Nicotiana glauca in Brazil
}

\author{
Gabriel Madoglio Favara ${ }^{1}$. Viviana Marcela Camelo-García ${ }^{1}$ Tatsuya Nagata ${ }^{2}$ - João Marcos Fagundes Silva ${ }^{2}$.

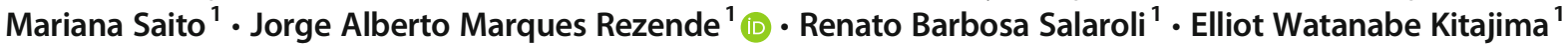

Received: 6 April 2019 / Accepted: 6 May 2019 /Published online: 10 May 2019

(C) Australasian Plant Pathology Society Inc. 2019

\begin{abstract}
Nicotiana glauca exhibiting very mild mottling on the leaves was found in the municipality of Piracicaba, state of São Paulo, Brazil. Transmission electron microscope analysis of symptomatic tissue, biological assay on virus indicator hosts, and near complete genome sequence indicated infection with the tobamovirus Tobacco mild green mosaic virus. To our knowledge this is the first report of the presence of this tobamovirus in Brazil.
\end{abstract}

Keywords Occurrence $\cdot$ Identification $\cdot$ Tobamovirus $\cdot$ Complete genome

The tobacco tree (Nicotiana glauca) is an herbaceous plant, native to South America, with some medical properties, used also as ornamental, but considered in some circumstances as invasive. A plant of $N$. glauca showing very mild mottling was found in a residential garden in Piracicaba municipality, state of São Paulo, Brazil (Fig. 1a). Suspecting a possible viral etiology, some leaves were collected and subjected to further analysis. Preliminary transmission electron microscopic examination of negatively stained leaf extract revealed abundant rod-shaped particles, $18 \mathrm{~nm}$ wide and ca. $300 \mathrm{~nm}$ long (Fig. 1b), suggesting infection by a tobamovirus. Examination of thin sections of symptomatic $N$. glauca leaf tissues confirmed the presence of large, parallel aggregates of rigid, elongated particles (Fig. 1c). Mechanical transmission assays of phosphatebuffered extracts of symptomatic $N$. glauca leaves resulted in local lesions in Chenopodium amaranticolor, C. quinoa, Datura stramonium, Gomphrena globosa, Nicotiana glutinosa

Elliot Watanabe Kitajima

jrezende@usp.br

1 Departamento de Fitopatologia e Nematologia, Escola Superior de Agricultura Luiz de Queiroz, Universidade de São Paulo, Piracicaba, SP 13418-900, Brazil

2 Departamento de Biologia Celular, Universidade de Brasília, Brasília, DF 70910-900, Brazil and $N$. tabacum cv. TNN. Inoculated N. glauca reproduced the systemic mild mottling, whereas systemic infection of $N$. tabacum cvs. Havana and Turkish caused severe mosaic. Inoculated plants of $N$. benthamiana resulted in initially symptomless infection, but the plant wilted and died two weeks after inoculation. Negatively stained extracts of all these symptomatic plants exhibited rod shaped particles under electron microscopic examination and sectioned leaf tissues exhibited aggregates of rod-shaped particles in the cytoplasm. The tobamovirus was partially purified by ammonium sulfate precipitation and the virus RNA isolated using the Purelink ${ }^{\circledR}$ viral RNA/DNA kit (Thermo Fisher Scientific, Waltham, USA). A cDNA library was prepared with the Illumina TruSeq Stranded mRNA Sample Prep LT Protocol (Illumina, San Diego, USA). The nucleotide sequencing was done in an Illumina HiSeq 2500 System at the Center of Functional Genomics (ESALQ/USP, Piracicaba, Brazil), using a HiSeq Flow Cell v4 and the HiSeq SBS v4 kit (Illumina) in paired-end mode, producing reads of $100 \mathrm{bp}(2 \mathrm{x} 100 \mathrm{bp})$. The near-complete genome has $6.352 \mathrm{nt}$ (GenBank MK005155) and showed $96.74 \%$ to $97.67 \%$ identities with corresponding nucleotide sequences from different isolates of Tobacco mild green mosaic virus (TMGMV) deposited on GenBank. RT-PCR assays on experimentally inoculated test plants, as well as the original sample of symptomatic $N$. glauca, using specific pair of primers for coat protein gene of TMGMV (Cohen et al. 2001) amplified fragments of expected size (455 bp), confirming the infection by this tobamovirus. TMGMV, originally described by McKinney (1929) in 
Fig. 1 Mild mottling on Nicotiana glauca $(\mathbf{a})$, rod-shaped particles, $18 \mathrm{~nm}$ wide and ca. $300 \mathrm{~nm}$ long, in negatively stained leaf extract of mechanically inoculated Chenopodium quinoa (b), large, parallel aggregates of rigid, elongated particles in thin section of leaf tissue of symptomatic Nicotiana glauca $(\mathbf{c})$
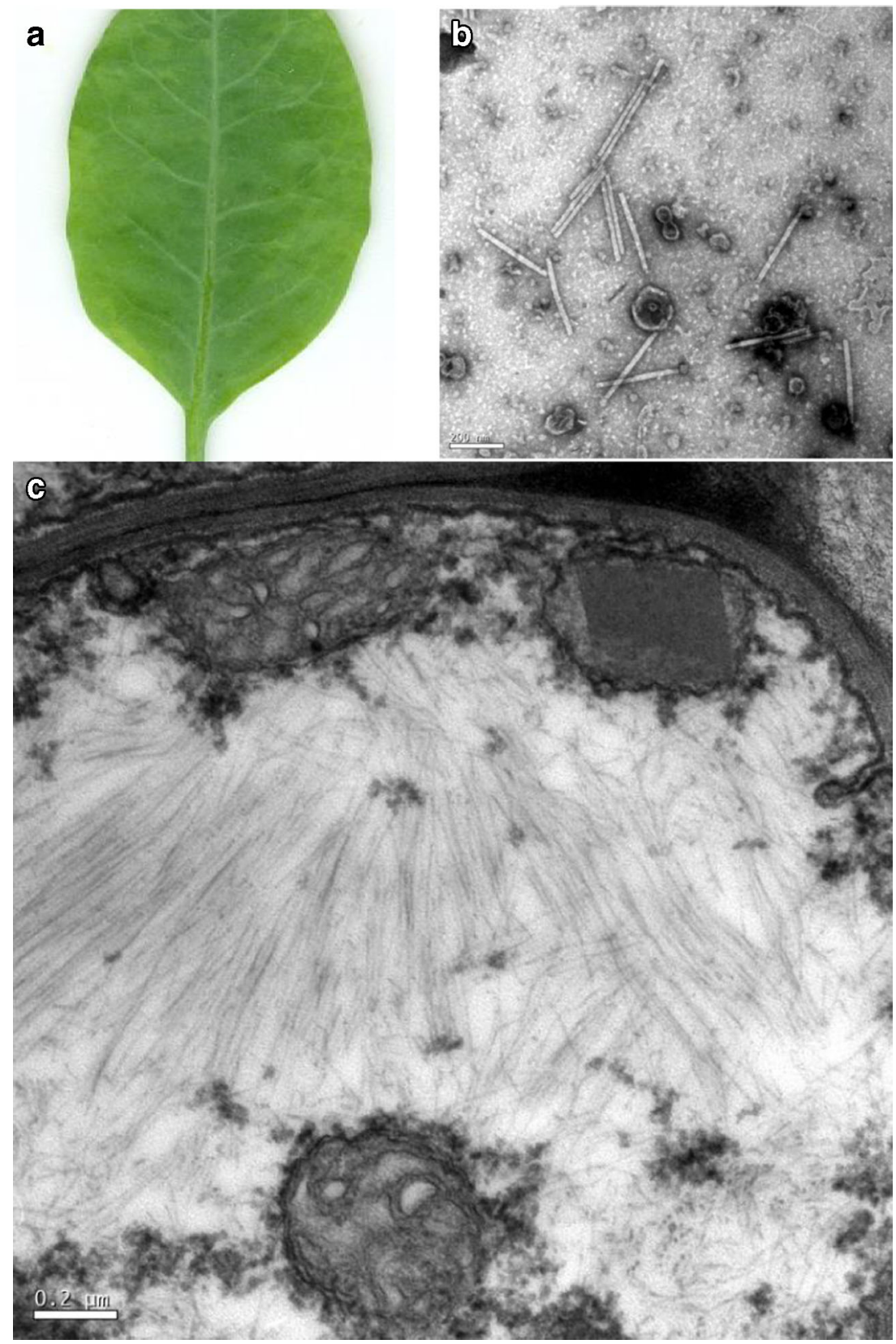

$N$. glauca in the Canary Island, has been detected infecting $N$. glauca in several parts of the world, as well as some cultivated plants, and considered of medium risk of potential economic losses (Skelton and Sansford 2012). This is the first report of the presence of TMGMV in Brazil.

Acknowledgements The present work was carried out with the support of Fundação de Amparo à Pesquisa no Estado de São Paulo 2017/189104. The presence of TMGMV in Brazil was notified to the Ministry of Agriculture (MAPA) of Brazil.

\section{References}

Cohen J, Rosner A, Kagan S, Lampel M, Maslenin L, Zeidan M, Gera A (2001) A new disease in Tabernaemontana associaed with Tobacco mild green mosaic virus. Ann Appl Biol 138:153-159. https://doi. org/10.1111/j.1744-7348.2001.tb00097.x

McKinney HH (1929) Mosaic diseases in the Canary Islands, West Africa and Gibraltar. J Agric Res 39:557-578

Skelton A, Sansford C (2012) Pest Risk Analysis for Tobacco mild green mosaic virus. The Food and Environmental Research Agency. https://secure.fera.defra.gov.uk/phiw/riskRegister/ downloadExternalPra.cfm?id=3924. Accessed 06 March 2019 